Article

\title{
Comparison of Respiratory and Ischemic Heart Mortalities and their Relationship to the Thermal Environment
}

\author{
Irmela Schlegel $^{1, *(\mathbb{D}}$, Stefan Muthers ${ }^{1} \mathbb{D}$, Hans-Guido Mücke ${ }^{2}$ and Andreas Matzarakis ${ }^{1}$ (D) \\ 1 Research Centre Human Biometeorology, Deutscher Wetterdienst, Stefan-Meier-Str. 4, \\ 79104 Freiburg, Germany; stefan.muthers@dwd.de (S.M.); andreas.matzarakis@dwd.de (A.M.) \\ 2 German Environment Agency, Department Environmental Hygiene, Corrensplatz 1, Berlin 14195, Germany; \\ hans-guido.muecke@uba.de \\ * Correspondence: Irmela.Schlegel@dwd.de; Tel.: +49-69-8062-9636
}

Received: 15 June 2020; Accepted: 2 August 2020; Published: 5 August 2020

check for updates

\begin{abstract}
Chronic respiratory and ischemic heart diseases are globally important parts of total mortality. This study focuses on the occurrence of mortality due to these disease groups in Germany and possible effects of the thermal environment. A retrospective analysis on the mortality rates of chronic lower respiratory diseases (CLRD) and ischemic heart diseases (IHD) at the regional level in Germany for the period 2001-2015 was done in combination with meteorological observations from the network of the German Meteorological Service. In order to control the mortality data for long-term and seasonal trends, a 365-day Gaussian low-pass filter with a filter response function was applied. The thermal environment was analysed using $2 \mathrm{~m}$ air temperature $\left(\mathrm{T}_{\mathrm{a}}\right)$ and the human biometeorological index Perceived Temperature (PT). The relationship of the Relative Risk (RR) of mortality to the thermal environment is displayed as an exposure-response curve, with threshold values at which RR increases significantly towards higher and lower temperature values. CLRD mortality increases above $17.6^{\circ} \mathrm{C}$, at approximately $4.4 \% /{ }^{\circ} \mathrm{C}(\mathrm{CI}: \pm 0.3)$. The increase of IHD mortality above the threshold of $18.8{ }^{\circ} \mathrm{C}$ is less steep, at $3.5 \% /{ }^{\circ} \mathrm{C}(\mathrm{CI}: \pm 0.2)$. During hot periods, CLRD mortality increases by $19.9 \%$, which is twice as much as IHD mortality, with an increase of $9.8 \%$. However, cold days and cold periods affect IHD slightly more than CLRD. The results highlight the concerns of CLRD patients during hot days as well as heat waves. This could lead to better precautions being taken for respiratory patients, which are already established for cardiac patients in Germany.
\end{abstract}

Keywords: excess mortality; respiratory diseases; COPD; ischemic heart diseases; heat stress; heat waves; heat-related mortality; cold impact; Germany

\section{Introduction}

Diseases of the upper and lower respiratory tracts are some of the most common diseases and causes of death in Germany. Acute respiratory tract infections, and particularly chronic diseases such as asthma and chronic obstructive pulmonary disease (COPD), have high social and economic importance in the health sector [1]. In the year 2015, mortality due to chronic lower respiratory diseases (CLRD, ICD-10 code J40-J47) accounted for approximately 35,095 deaths, $88.5 \%$ of which had a COPD (ICD code J44) as the main cause, and 3\% of which were due to bronchial asthma (J45-J46) [2]. COPDs are hypersensitivity conditions of the bronchial mucosa; bronchial inflammation triggers mostly chronic and irreparable damage of the pulmonary tissue [3]. While COPD affects mostly elderly people, bronchial asthma also affects children [4]. 
Mortality due to CLRD shows an increasing trend in Germany. The number of deaths in the year 2015 represented a $47 \%$ increase compared to 2001 . Deaths caused by asthma have decreased by $61 \%[2,5]$. The increasing trend in COPD mortality requires an investigation of relevant impact factors.

Ischemic heart diseases (IHD, ICD-10 code I20-I25), also known as coronary heart diseases, are the most common cause of death in Germany, with the number of cases being 3.6 times as high as deaths from CLRD. However, IHD mortality has decreased in the last 15 years in Germany; mortality in 2015 was $22 \%$ lower in comparison to $2001[2,5]$.

Many studies have analysed the effects of weather on mortality due to cardiovascular (including IHD) and respiratory diseases, and have described a relationship with thermal conditions. The relationship between air temperature and mortality is often characterized by a U- or J-shaped curve, with increasing mortality towards colder and warmer temperature values, as well as an optimal area in the middle of the temperature range (e.g., $[6,7])$. The mortality risk due to heat has been extensively analysed.

In recent decades, an increasing frequency of heat waves has been observed. Both summer 2003 and 2015 have received particular attention due to the pronounced heat events and their health impacts, especially in Western and Central Europe [8]. Germany was affected by both heat waves, particularly in its southern regions. The average summer (June, July, and August, JJA) air temperature $\left(T_{a}\right)$ anomaly value for Germany was $3.4^{\circ} \mathrm{C}$ for 2003 and $2.1^{\circ} \mathrm{C}$ for 2015 , with respect to the reference period 1961-1990 [9]. In Southwest Germany (State of Baden-Württemberg), the daily mortality rate showed anomalies of up to 70\% in August 2003 and 56\% in July 2015 [8]. In particular, high associations were found for the 2003 heat wave with respiratory mortality [10].

Understanding the risks of extreme thermal conditions like heat events on human health is an important key to prepare adaptation processes for people and societies in order to confront the projected increase in heat period intensity, frequency, and duration [11]. IHD and CLRD are important parts of total mortality in Germany and are especially interesting in relation to heat and cold; therefore, these disease groups were chosen for analysis and comparison. The physiological impact of heat stress on the cardiovascular system, and therefore on chronic heart patients, is well known (e.g., [12-16]). In Germany, the effects of heat events on IHD in recent and future years have been analysed [7,17-19], and awareness of the vulnerability during heat periods is high. For chronic respiratory diseases with much lower mortality cases than IHD, this knowledge is not very prevalent in Germany, and the awareness of the risk due to heat stress is less communicated.

In order to analyse the relationship between mortality and the thermal environment, which is defined as the interactions of several parameters representing thermal conditions, the human biometeorological index Perceived Temperature (PT) $[20,21]$ is used in this study in comparison to the $2 \mathrm{~m}$ air temperature $\left(\mathrm{T}_{\mathrm{a}}\right) . \mathrm{T}_{\mathrm{a}}$ is internationally more common and allows for better comparison between studies.

The aim of this study is to classify the impacts of the thermal environment on chronic lower respiratory diseases in comparison to ischemic heart diseases in Germany. A further objective is to compare PT and $\mathrm{T}_{\mathrm{a}}$ in terms of aptitude. First, the relationship of the full temperature range with CLRD and IHD mortality is compared, particularly focusing on the increases of mortality during warm and cold thermal conditions. To elucidate this reaction, the impacts of heat and cold events on mortality are analysed. To reify this risk with an example, a comparison of the occurrence of IHD and CLRD mortality rates during the 2003 and 2015 heat waves is done for seven regions in Germany. The results arising from the comparison of these two disease groups could raise awareness of the risks that people with chronic respiratory diseases have during hot days and heat periods. 


\section{Materials and Methods}

\subsection{Data}

Mortality data for Germany was obtained from the Research Data Centre of the Statistical Offices of the Federal States of Germany for the years 2001-2015. The spatial resolution comprises seven regions in Germany, in order to account for differences in climate conditions and population density (Figure 1). Mortality data of IHD are available daily for ICD-10 (International Statistical Classification of Diseases version 10) code I20-I25 as a collective group (Table 1). Mortality due to CLRD with ICD-10 code J40-J47 are available in a temporal resolution of two-day sums, because of a lower number of cases on single days.

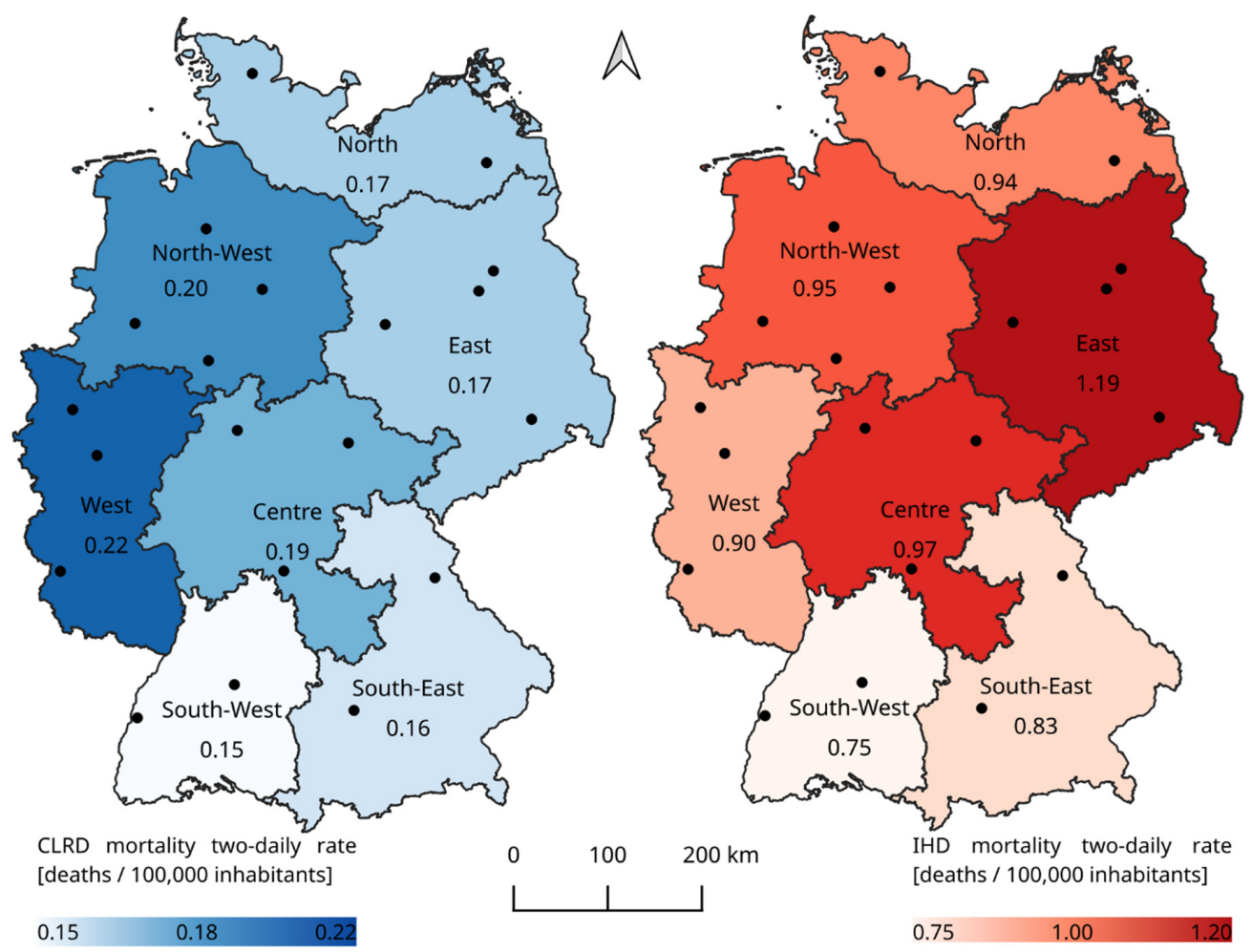

Figure 1. Spatial resolution and two-daily rate (two-daily sum of deaths per 100,000 inhabitants) of chronic lower respiratory diseases (CLRD) mortality (J40-J47, blue, left) and ischemic heart diseases (IHD) mortality (I20-I25, red, right) data in seven regions in Germany. The black dots display the locations of 20 meteorological stations.

Meteorological data from 20 synoptic weather stations of the German Meteorological Service (DWD) network is used (black dots in Figure 1). Criteria for the selection of stations were data availability with regard to the period 2001-2015 and the requirements of PT as well as the population under investigation. The selected representative stations are in accordance with the official weather station criteria of the World Meteorological Organisation, therefore, an urban influence can be broadly excluded. Data of stations within the same region were averaged in hourly resolution, to compute a representative time series for each region. Missing data was filled with linear interpolation (short data gaps), or by data of stations within the same region. Subsequently, the daily average $\mathrm{T}_{\mathrm{a}} / \mathrm{PT}$ was generated. This led to complete time series for the seven regions, without missing values.

In order to assess the relationship between the thermal environment and health effects, PT from DWD is used as human biometeorological index additionally (for the method, see supplement chapter $\mathrm{B}$ [20-22]). However, the correlation coefficient of PT and $T_{a}$ in this analysis is $r=0.99$, probably due to the use of daily mean values eliminating the biggest differences of PT to $\mathrm{T}_{\mathrm{a}}$. The correlation of PT 
and $\mathrm{T}_{\mathrm{a}}$ decreases (0.90) if only high or low temperature ranges are analysed for heat and cold waves. Therefore, PT is analysed additionally in comparison to $\mathrm{T}_{\mathrm{a}}$. Because of the higher spatial coverage of $\mathrm{T}_{\mathrm{a}}$, which is also more commonly used internationally, the following results are presented based on $\mathrm{T}_{\mathrm{a}}$; results of PT are displayed in the supplement.

Table 1. Total number and two-daily averages of deaths due to chronic lower respiratory diseases (CLRD, blue) and ischemic heart diseases (IHD, red), as well as two-daily rate (deaths per two days and 100,000 inhabitants), in seven regions of Germany, in the period 2001-2015.

\begin{tabular}{ccccccc}
\hline \multirow{2}{*}{ Region } & \multicolumn{2}{c}{$\begin{array}{c}\text { Total Number of Deaths } \\
\text { 2001-2015 }\end{array}$} & \multicolumn{2}{c}{ Two-Day Average } & \multicolumn{2}{c}{$\begin{array}{c}\text { Deaths Per Two-Day and } \\
\mathbf{1 0 0 , 0 0 0} \text { Inhabitants (rate) }\end{array}$} \\
\cline { 2 - 7 } & CLRD & IHD & CLRD & IHD & CLRD & IHD \\
\hline Germany & 419,589 & $2,102,169$ & 153 & 767 & 0.19 & 0.93 \\
North & 29,673 & 161,020 & 10 & 57 & 0.17 & 0.94 \\
North-West & 73,785 & 343,262 & 26 & 124 & 0.20 & 0.95 \\
East & 59,088 & 408,354 & 20 & 147 & 0.17 & 1.19 \\
West & 111,485 & 451,346 & 39 & 162 & 0.22 & 0.90 \\
Centre & 58,024 & 301,360 & 20 & 108 & 0.19 & 0.97 \\
South-West & 45,105 & 220,814 & 16 & 80 & 0.15 & 0.75 \\
South-East & 42,429 & 216,013 & 15 & 78 & 0.16 & 0.83 \\
\hline
\end{tabular}

\subsection{Definition of Expected Value/Relative Risk}

In order to compare CLRD and IHD mortality, IHD mortality was transformed to two-daily temporal resolutions as well. This accounts also for the time lag of the impact of thermal stress to human health between 0 and 1 day. Mortality data display a long-term trend over the years 2001-2015 and seasonal variations, mostly with a maximum of cases in winter and a minimum in summer (CLRD mortality see Figure 2, for IHD mortality see Supplementary Figure S1). To compare the data of different regions, a two-daily population-based rate of deaths per 100,000 inhabitants is used, which eliminates the influence of changing population as well.

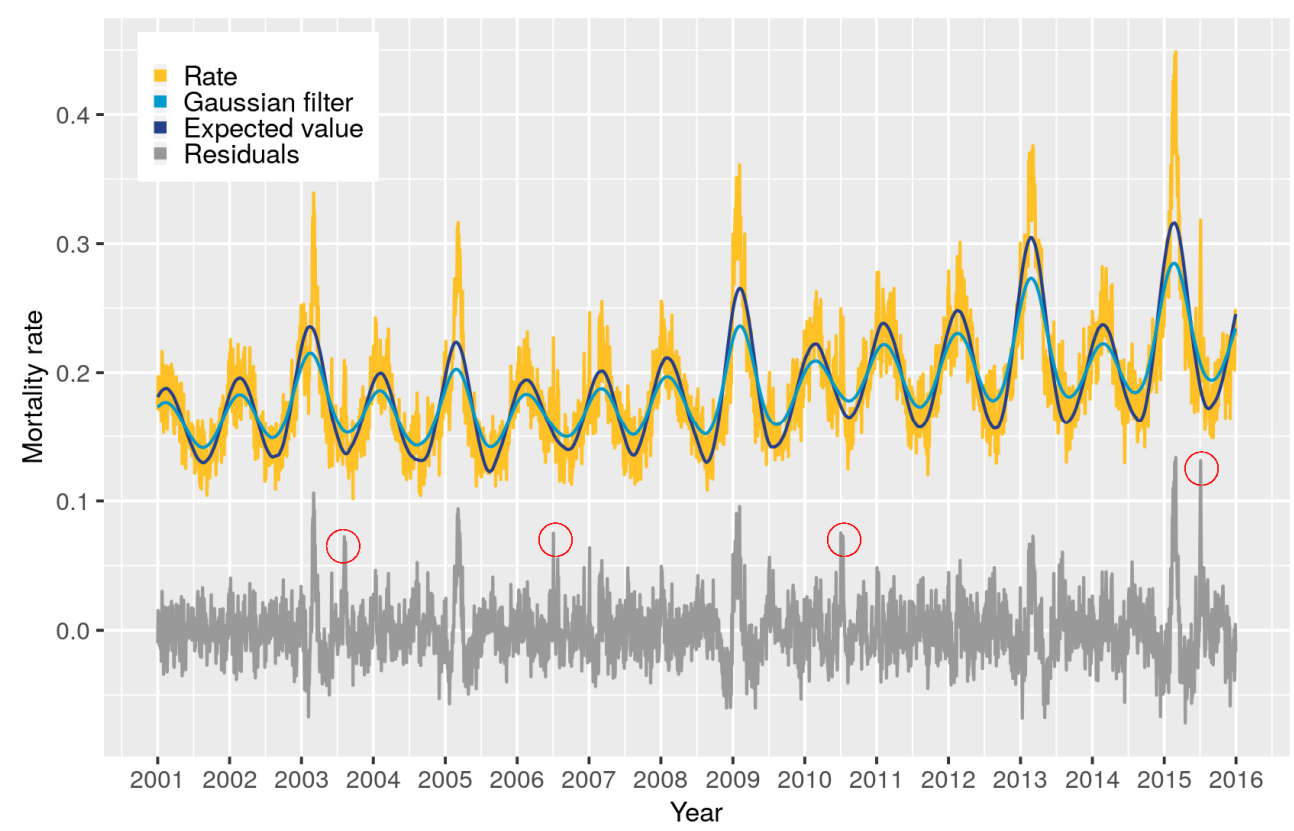

Figure 2. Expected value of CLRD mortality with population-based two-day rate (yellow), result of the Gaussian low-pass filter (light blue), the corrected filter function of expected value (dark blue) and the residuals (grey). Marked in red are the deviations of mortality during the summers 2003, 2006, 2010 and 2015. 
In order to control mortality data of long-term trends and seasonal variations, a method developed by [23] was applied. This method applies a 365-day Gaussian low-pass filter with a filter response function to calculate the expected mortality $[24,25]$.

The smoothing function results in an underestimation of minima and maxima, which is adjusted by a correction factor suggested by [26]. With this corrected filter function, the expected value of mortality and the excess-mortality, i.e. the difference between observed and expected mortality, is derived [23]. In order to account for the two-daily mortality rates, the length of the Gaussian filter had been changed to 182 . Due to very weak variations of mortality data with the day of the week, a weekly cycle was not included as a confounding variable. In Figure 2, the steps of the methods are displayed for CLRD mortality. Figure 2 also displays the increasing trend of CLRD mortality and the impacts of heat periods of the summers 2003, 2006, 2010 and 2015 in increased rates and residuals.

The Relative Risk (RR) expresses the mortality risk by referring the residuals to the expected mortality (Equation (1)). RR is independent of long-term trends and seasonal variations and used for evaluation. All calculations and plot generating was performed using R version 3.6 .2 [27].

$$
\mathrm{RR}=1+\text { residuals/expected value }
$$

\subsection{Relationship between $R R$ and Thermal Environment}

Air temperature associated with the two-daily mortality was chosen as two-daily mean as well, but with a lag of one single day (Figure 3). This was done to avoid a leading connection between temperature of day 2 and mortality of day 1, and to consider a lag effect of one to two days in the relationship between mortality and temperature. This association of two-daily mortality and two-day average of $T_{a}$ is termed as "twin-day" in the following, as well as "Lag 0-1" in the lag analysis.

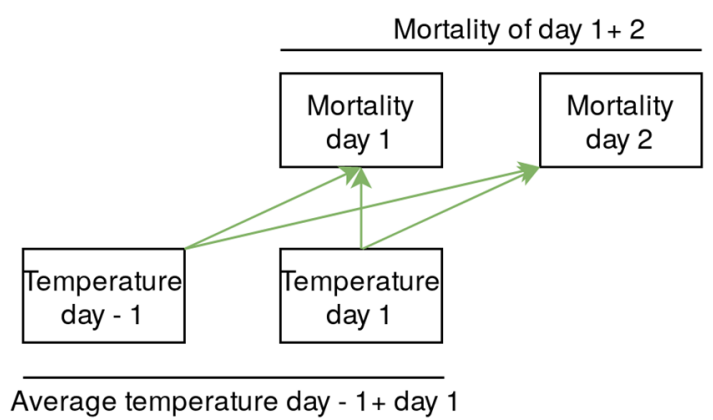

Figure 3. Association between two-day average of temperature and two-daily mortality, with consideration of lag effects avoiding a leading connection between day-1-mortality and day-2-temperature.

The relationship between thermal environment and mortality is analysed by an exposure-response curve. For this, two-daily mean of $\mathrm{T}_{\mathrm{a}}$ is classified into $3 \mathrm{~K}$ intervals, for which mean of RR, standard deviation and the 95th percentile is calculated. To ensure a continuous course of the relationship, the intervals are shifted with a step size of $0.1 \mathrm{~K}$. For the exposure-response analysis, only intervals comprising a minimum of 30 days are considered, to avoid intervals with low data volume. To analyse a lagged reaction of mortality to the thermal environment, the exposure-response relationship is additionally generated with temperature average of the past 12 days (i.e., 6 twin-days).

With the exposure-response relationship, threshold values (TH) can be defined. In case of a mortality minimum in the middle of the temperature range (temperature optimum) and increase to the warmer and colder temperature range, an upper threshold value $\left(\mathrm{TH}_{U}\right)$ and a lower threshold value $\left(\mathrm{TH}_{\mathrm{L}}\right)$ can be derived. These $\mathrm{TH}$ mark the temperature at which $\mathrm{RR}$ is the first time significantly greater than one (tested with student's $t$-test with a significance level of $95 \%$ ), starting from the minimum in the direction of colder and warmer temperature values. Linear regression models were used to generate gradients of $\mathrm{RR}$ above $\mathrm{TH}_{\mathrm{U}}$ and below $\mathrm{TH}_{\mathrm{L}}$, to assess the increase/decrease of $\mathrm{RR}$ with 
increasing/decreasing temperatures. These gradients apply regardless of whether $R R$ is significantly different to one.

\subsection{Definition of Heat and Cold Waves}

Due to the two-day resolution of mortality data, heat waves are defined as a minimum of two consecutive twin-days with two-daily mean of $\mathrm{T}_{\mathrm{a}}$ exceeding the 95th percentile. Cold waves are defined as a minimum of two consecutive twin-days with $T_{a}$ below the 5 th percentile. The percentiles were estimated regionally using all $\mathrm{T}_{\mathrm{a}}$ values between 2001-2015.

\section{Results}

\subsection{Relationship between Mortality and Thermal Environment}

CLRD and IHD mortality both display a J-shaped relationship to $\mathrm{T}_{\mathrm{a}}$ (Figure 4). For CLRD mortality, a temporary increase of mortality is found for $\mathrm{T}_{\mathrm{a}}$ values below the $\mathrm{TH}_{\mathrm{L}}$ of $-2.7^{\circ} \mathrm{C}$ (Table 2), however, with further decreasing $\mathrm{T}_{\mathrm{a}}, \mathrm{RR}$ is decreasing as well. The linear gradient of $\mathrm{RR}$ below $\mathrm{TH}_{\mathrm{L}}$ is $-0.2 \% /{ }^{\circ} \mathrm{C}$ for the mean values of Germany. Within the regions, the $\mathrm{TH}_{\mathrm{L}}$ ranges between -4.2 and $1.7^{\circ} \mathrm{C}$; for the regions North, West and Centre, no significant RR increase can be found for the lower temperature range. Despite the existence of significant $\mathrm{TH}_{\mathrm{L}}$, no significant gradient below the $\mathrm{TH}_{\mathrm{L}}$ was found in some regions. This is due to a non-continuous progress of $R R$, or due to a lower occurrence of extreme temperatures in the regions. The minimum of RR (temperature optimum) occurs at about $12{ }^{\circ} \mathrm{C}$. The $\mathrm{TH}_{\mathrm{U}}$ for CLRD in Germany is $17.6^{\circ} \mathrm{C}$, and varies between $16.0^{\circ} \mathrm{C}$ and $19.5^{\circ} \mathrm{C}$ for the different regions (Table 2). Above $\mathrm{TH}_{\mathrm{U}}$, $\mathrm{RR}$ increases strongly with $4.4 \% /{ }^{\circ} \mathrm{C}$. However, Figure 4 shows that the linear gradient is only suitable to a limited extend for the more exponential curve of increasing RR.

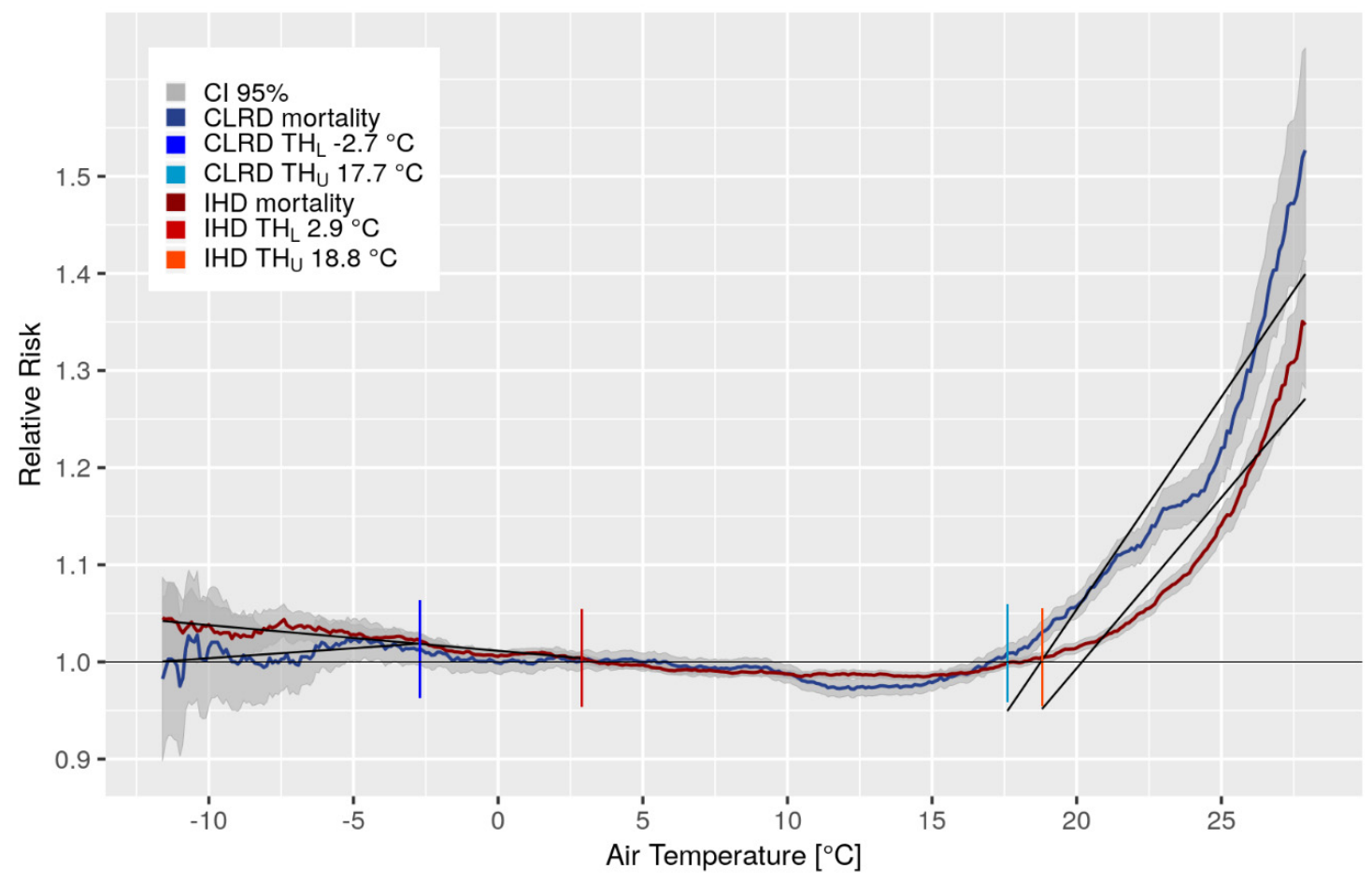

Figure 4. Relationship between $\mathrm{T}_{\mathrm{a}}$ and Relative Risk (RR) of CLRD and IHD mortality in the years 2001-2015 in Germany. 
Table 2. Lower $\left(\mathrm{TH}_{\mathrm{L}}\right)$ and upper $\left(\mathrm{TH}_{\mathrm{U}}\right)$ threshold values of $\mathrm{T}_{\mathrm{a}}$ of CLRD mortality (blue) and IHD mortality (red), as well as the gradients of RR below resp. above these TH for Germany and its seven regions. Significant gradients on $95 \%$ level $(\alpha=0.05)$ are marked in bold.

\begin{tabular}{ccccccccc}
\hline Region & \multicolumn{3}{c}{$\mathrm{T}_{\mathbf{a}}$ Thresholds $\left({ }^{\circ} \mathbf{C}\right)$} & \multicolumn{3}{c}{ Gradients of RR Below/Above TH $\left(\% /{ }^{\circ} \mathbf{C}\right)(\mathbf{C I})$} \\
\hline & \multicolumn{2}{c}{ CLRD } & \multicolumn{2}{c}{ IHD } & \multicolumn{2}{c}{ CLRD } & \multicolumn{2}{c}{ IHD } \\
\hline & $\mathrm{TH}_{\mathrm{L}}$ & $\mathrm{TH}_{\mathrm{U}}$ & $\mathrm{TH}_{\mathrm{L}}$ & $\mathrm{TH}_{\mathrm{U}}$ & $<\mathrm{TH}_{\mathrm{L}}$ & $>\mathrm{TH}_{\mathrm{U}}$ & $<\mathrm{TH}_{\mathrm{L}}$ & $>\mathrm{TH}_{\mathrm{U}}$ \\
\hline Germany & -2.7 & 17.6 & 2.9 & 18.8 & $\mathbf{0 . 2}( \pm 0.1)$ & $4.4( \pm 0.3)$ & $-\mathbf{0 . 3}( \pm 0.0)$ & $3.5( \pm 0.2)$ \\
North & - & 16.0 & -6.4 & 20.3 & - & $3.7( \pm 0.3)$ & $-*$ & $2.6( \pm 0.3)$ \\
North-West & 1.7 & 18.0 & 2.4 & 18.3 & $-0.1(0.2)$ & $3.6( \pm 0.2)$ & $-\mathbf{0 . 6}( \pm 0.1)$ & $\mathbf{2 . 1}( \pm 0.2)$ \\
East & -4.1 & 18.5 & 2.4 & 20.1 & $0.5( \pm 0.3)$ & $\mathbf{1 . 9}( \pm 0.2)$ & $0.0( \pm 0.0)$ & $2.9( \pm 0.2)$ \\
West & - & 18.5 & 3.4 & 19.3 & - & $3.5( \pm 0.2)$ & $-\mathbf{0 . 2}( \pm 0.0)$ & $3.0( \pm 0.3)$ \\
Centre & - & 18.5 & 2.1 & 20.3 & - & $3.2( \pm 0.2)$ & $-\mathbf{0 . 3}( \pm 0.0)$ & $2.6( \pm 0.1)$ \\
South-West & 0.7 & 19.5 & -0.1 & 20.1 & $0.0( \pm 0.1)$ & $2.8( \pm 0.2)$ & $-\mathbf{0 . 3}( \pm 0.1)$ & $\mathbf{2 . 2}( \pm 0.2)$ \\
South-East & -4.2 & 18.0 & -2.2 & 17.4 & $-0.3( \pm 0.4)$ & $3.3( \pm 031)$ & $-\mathbf{0 . 4}( \pm 0.1)$ & $\mathbf{1 . 5}( \pm 0.1)$ \\
\hline
\end{tabular}

${ }^{*}$ Due to the regional $\mathrm{TH}_{\mathrm{L}}$ at an extreme low temperature, data volume below this $\mathrm{TH}_{\mathrm{L}}$ was insufficient to generate a gradient of RR.

For IHD mortality, a similar relationship to $\mathrm{T}_{\mathrm{a}}$ is found (Figure 4). The averaged $\mathrm{TH}_{\mathrm{L}}$ for Germany is $2.9^{\circ} \mathrm{C}$, with a linear gradient of $-0.3 \% /{ }^{\circ} \mathrm{C}$ below $\mathrm{TH}_{\mathrm{L}}$ (Table 2). In comparison to CLRD mortality, the increase of IHD mortality towards lower $\mathrm{T}_{\mathrm{a}}$ is significant and more continuous resulting in a higher cold-related IHD mortality (Figure 4). Minimum of RR for IHD mortality is at about $14{ }^{\circ} \mathrm{C}$, the $\mathrm{TH}_{\mathrm{U}}$ at $18.8^{\circ} \mathrm{C}$. Compared to CLRD, the linear gradient of IHD mortality above $\mathrm{TH}_{U}$ of $3.5 \% /{ }^{\circ} \mathrm{C}$ is less steep, which leads to a lower heat-related mortality due to IHD compared to CLRD.

The regional results reveal partly different tendencies between IHD and CLRD mortality. Region North-West represents higher $\mathrm{TH}_{\mathrm{L}}$ and higher sensitivity to cold for both IHD and CLRD, region West for IHD and region South-West for CLRD. However, despite low $\mathrm{TH}_{\mathrm{L}}$, increase of RR below these $\mathrm{TH}_{\mathrm{L}}$ is strong in regions South-East and South-West for IHD. Lower $\mathrm{TH}_{\mathrm{U}}$ are displayed in regions North-West and South-East for both IHD and CLRD, in region North only for CLRD. However, a $\mathrm{TH}_{\mathrm{U}}$ at a higher $T_{a}$ is not necessarily synonymous to a lower sensitivity to heat displayed in the gradient of $\mathrm{RR}$ above $\mathrm{TH}_{\mathrm{U}}$, e.g., in region North for IHD mortality.

The relationship between mortality and the thermal environment can change if lag effects are considered. Therefore, a delay in response to the thermal environment for up to 12 days is examined in Figure 5. In the cold temperature range, the consideration of Lag 0-12 leads to higher RR of especially CLRD and only slightly of IHD mortality (Figure 5). Between about $0{ }^{\circ} \mathrm{C}$ and $20^{\circ} \mathrm{C}$, almost no lag effect is visible. In the higher temperature range, the lag effect leads to increasing RR compared to Lag $0-1$ as well. This effect at warm and hot days is slightly stronger than the effect at cold days.

The relationship between mortality and PT reveal a similar exposure-response curve with slight differences in threshold values $\left(\mathrm{TH}_{\mathrm{L}}\right.$ and $\left.\mathrm{TH}_{\mathrm{U}}\right)$ and gradients of $\mathrm{RR}$, above and below the thresholds attributable to the parameter used (see Supplementary Figure S2 and Table S1). 


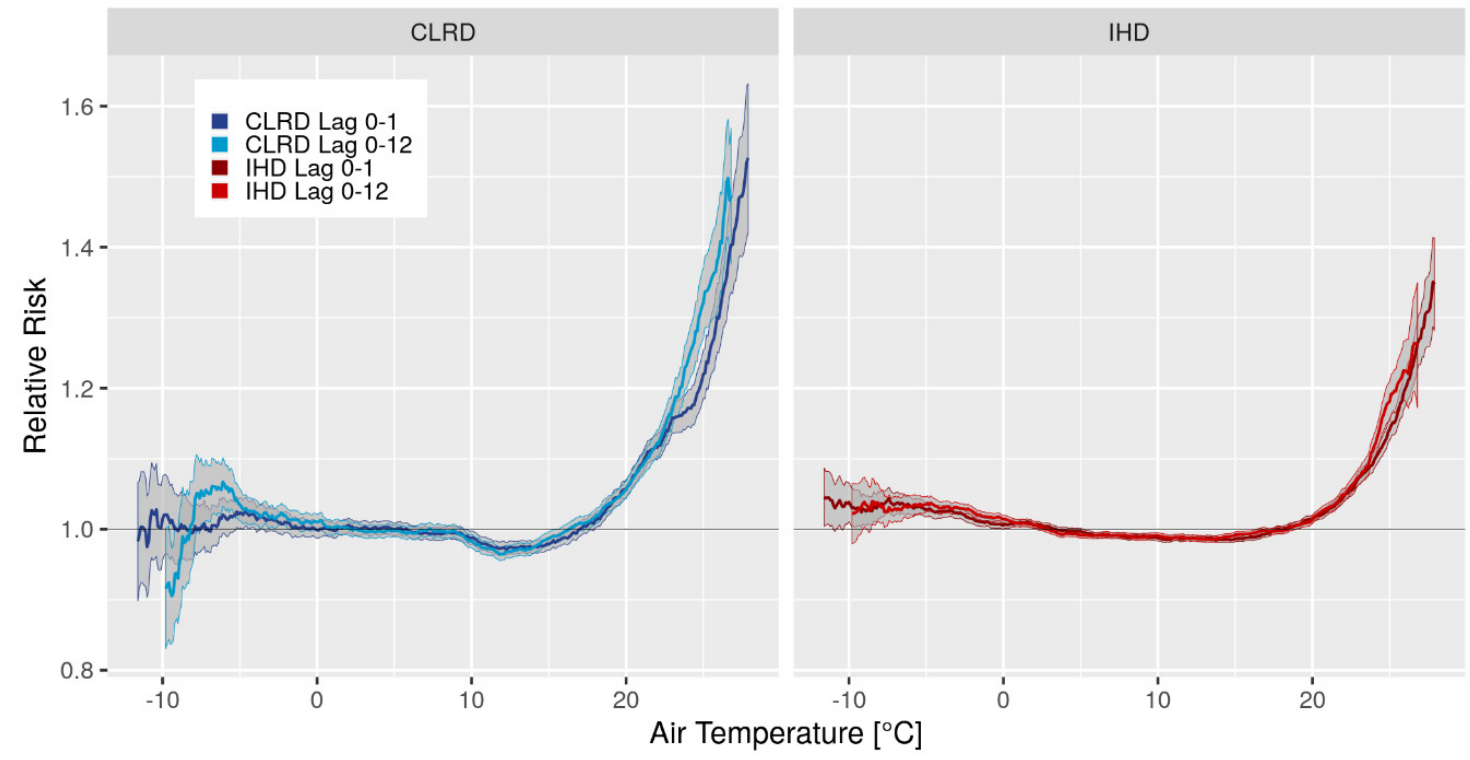

Figure 5. Relationship between Chronic lower respiratory diseases (CLRD) resp. ischemic heart diseases (IHD, red) mortality and air temperature, considering lag effects of the past 12 days (Lag 0-12 corresponds to the average temperature impact of 6 twin-days before days of mortality).

\subsection{Heat Waves}

Due to the increased risk at high temperature ranges, heat waves are periods of special concern for patients with CLRD and IHD. The 95th percentile averaged over the seven regions in Germany for the years $2001-2015$ amounts to $21.0^{\circ} \mathrm{C}$; the averaged $\mathrm{T}_{\mathrm{a}}$ during heat waves is $23.1{ }^{\circ} \mathrm{C}$ (Table 3 ). Comparing the days identified as heat waves based on $\mathrm{T}_{\mathrm{a}}$ or PT, approximately $90 \%$ of days are compliant, meaning that $90 \%$ of dates identified as associated to heat waves by $\mathrm{T}_{\mathrm{a}}$ are identified by PT as well (see Chapter $\mathrm{C}$ in the supplement).

Table 3. Deviation of CLRD (blue) and IHD (red) mortality during heat waves based on $\mathrm{T}_{\mathrm{a}}$. Significant deviations on $95 \%$ level $(\alpha=0.05)$ are marked in bold.

\begin{tabular}{ccccc}
\hline & & & CLRD & IHD \\
\hline Region & 95th Percentileof $\mathbf{T}_{\mathbf{a}}\left({ }^{\circ} \mathbf{C}\right)$ & Average $\mathbf{T}_{\mathbf{a}}\left({ }^{\circ} \mathbf{C}\right)$ & Deviation of Mortality $(\%)$ & Deviation of Mortality $(\%)$ \\
\hline Germany & 21.0 & 23.1 & 19.9 & 9.8 \\
North & 19.7 & 21.5 & 23.1 & 5.7 \\
North-West & 20.6 & 22.8 & 18.9 & 9.0 \\
East & 21.5 & 23.9 & 17.7 & 11.5 \\
West & 20.9 & 23.1 & 22.0 & 11.9 \\
Centre & 20.9 & 23.2 & 20.9 & 9.6 \\
South-West & 22.1 & 23.9 & 21.0 & 10.3 \\
South-East & 20.7 & 22.6 & 15.2 & 7.1 \\
\hline
\end{tabular}

The average duration of heat waves is 3.4 twin-days occurring in one or several regions in Germany. On average, three events per year occurred in Germany; within the regions, two events per year occurred. During heat waves, a significant increase of mortality by $19.9 \%$ for CLRD and $9.8 \%$ for IHD mortality is found, when averaging over all heat waves between 2001-2015 (Figure 6 left and Table 3). Increase of mortality starts instantaneous with the onset of the heat wave, and increases further with mounting duration. After day $7 / 8$ however, increase is interrupted. CLRD mortality shows deviations of about $15.2 \%$ at day $1 / 2$ and up to $33.2 \%$ at day $13 / 14$. The regional analysis reveals that region South-East and region East are less affected by heat-related CLRD mortality than the other regions, while for the regions North, West, Centre and South-West the largest effects of heat waves on CLRD mortality are found (Table 3). 

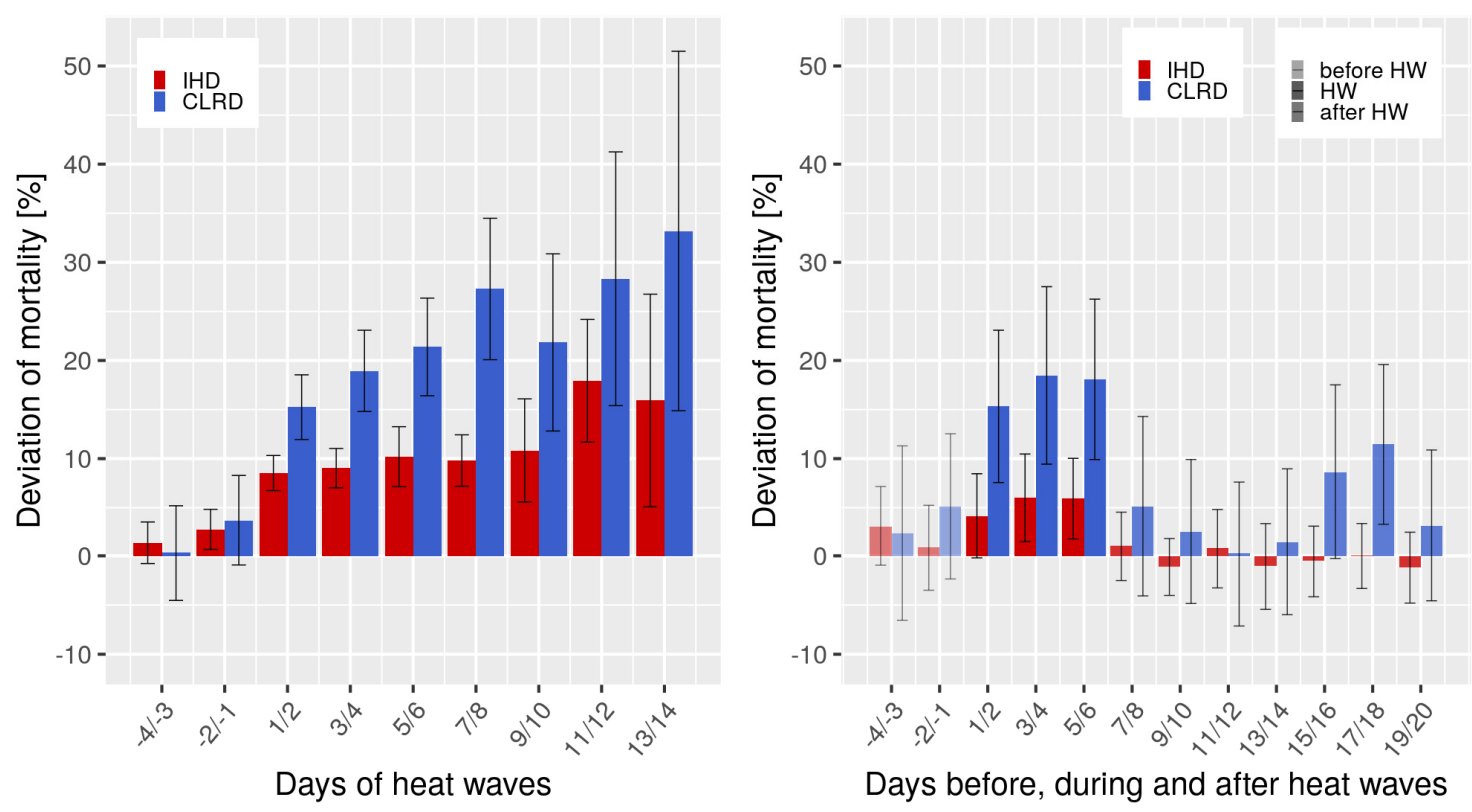

Figure 6. Deviation of CLRD and IHD mortality from the expected value due to heat waves based on $\mathrm{T}_{\mathrm{a}}$. Left: Averaged over all heat waves between 2001-2015 in Germany. Right: Days before, during and after 6-day (3 twin-days) heat waves in Germany averaged over the years 2001-2015.

Increase of IHD mortality is about half as much as for CLRD mortality. During heat waves, the deviation is between $8.5 \%$ at day $1 / 2$, and up to $17.9 \%$ at day $11 / 12$. The regional distribution of heat-related IHD mortality is partly different to CLRD mortality: the regions West, Centre and South-West are also the most affected regions, but likewise, region East is affected. North and South-East are less affected.

Health effects of heat waves can occur also after the heat wave itself. To analyse this lagged effect, the temporal development of mortality before, during and after heat waves is exemplarily displayed for heat waves with a duration of 6 days (three consecutive twin-days) in Figure 6 (right). At the beginning of heat waves, CLRD mortality is rising strongly up to $18.5 \%$ at day $3 / 4$. IHD mortality increases as well, but the maximal deviation is $6.0 \%$ at day $3 / 4$. After the 6 -days heat waves, the deviation of mortality is not anymore significantly increased. Despite decreasing mortality after heat waves, the deviation drops not significantly below the expected value. Consequently, no significant effect of mortality displacement could be found for the days following 6-days heat waves.

Analysing heat waves on the bases of PT, deviations of mortality are similar. However, the differences between the regions increase with higher mortality impact in the regions West, Centre and South-West and lower deviations in the other regions. This trend is found mainly for CLRD mortality and less for IHD mortality (see Supplementary Figure S3 and Table S3).

\subsection{Cold Waves}

Especially respiratory diseases are linked to cold weather and breathing cold air. However, symptoms of IHD can be intensified during cold periods as well. The 5th percentile averaged over the seven regions in Germany for the years $2001-2015$ amounts to $-2.0^{\circ} \mathrm{C}$ (Table 4). The mean of $\mathrm{T}_{\mathrm{a}}$ during the cold waves is $-4.6^{\circ} \mathrm{C}$. The average duration of cold waves is 3.7 twin-days, occurring in one or several regions in Germany. On average, three events per year occurred in Germany; within the regions, two events occurred.

Averaged over the years 2001-2015, a significant increase of CLRD mortality compared to the expected value was found for Germany, with an average deviation of $1.9 \%$ and a maximum of $10.0 \%$ at day 9/10 (Figure 7). Of the seven regions, only North-West displays a significant cold effect. 
Table 4. Deviation of CLRD (blue) and IHD (red) mortality during cold waves based on $\mathrm{T}_{\mathrm{a}}$. Significant deviations on $95 \%$ level $(a<0.5)$ are marked in bold.

\begin{tabular}{ccccc}
\hline & & & CLRD & IHD \\
\hline Region & 5th Percentile of $\mathbf{T}_{\mathbf{a}}\left({ }^{\circ} \mathbf{C}\right)$ & Average $\mathbf{T}_{\mathbf{a}}\left({ }^{\circ} \mathbf{C}\right)$ & Deviation of Mortality $(\%)$ & Deviation of Mortality $(\%)$ \\
\hline Germany & -2.0 & -4.6 & 1.9 & 2.8 \\
North & -2.3 & -4.8 & 2.6 & 3.8 \\
North-West & -1.4 & -3.9 & 3.4 & 3.4 \\
East & -2.6 & -5.5 & 1.7 & 1.1 \\
West & -0.8 & -3.2 & 0.6 & 2.5 \\
Centre & -2.7 & -5.5 & 1.7 & 2.7 \\
South-West & -1.7 & -4.2 & 1.0 & 4.2 \\
South-East & -3.9 & -6.6 & 3.2 & 2.7 \\
\hline
\end{tabular}

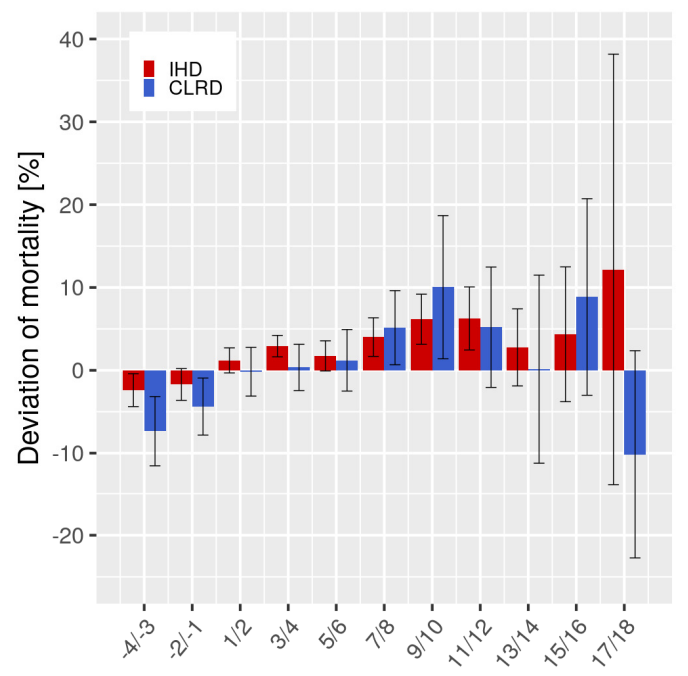

Days of cold waves

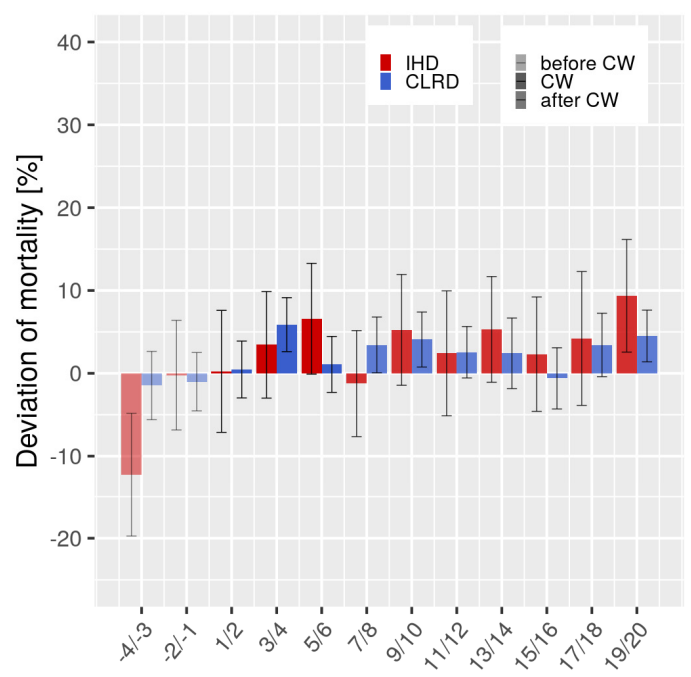

Days before, during and after cold waves

Figure 7. Deviation of CLRD and IHD mortality from the expected value due to cold waves based on $\mathrm{T}_{\mathrm{a}}$. Left: Averaged over all cold waves between 2001-2015 in Germany. Right: Days before, during and after 6-day (3 twin-days) cold waves in Germany averaged over the years 2001-2015.

In contrast to heat waves, IHD mortality displays a slightly higher cold effect than CLRD mortality, with a significant increase by $2.8 \%$ (Table 4 ) and a maximum of $6.2 \%$ at day $11 / 12$ (Figure 7 ). All but one region (East) have a significant deviation of mortality during cold waves between $2.5 \%$ and $4.2 \%$. To evaluate the effect of extreme cold conditions, a lagged response has to be considered. The analysis of 6-days cold waves ( 3 twin-days) shows that the increase of mortality does not only occur during the cold waves, but in the days following the cold wave. The increase, however, is mostly not significant.

Analysing cold waves based on PT, the agreement between days identified as cold waves by PT and $\mathrm{T}_{\mathrm{a}}$ is $88 \%$. For CLRD and IHD mortality, equally low effects of cold waves based on PT were found (see Supplementary Table S4, Figure S4 and Table S5).

\subsection{Comparing 2003 and 2015 Heat Waves}

In August 2003, an intense and long-lasting heat wave occurred in all seven regions of Germany (Figure 8). Beginning on 30 July or 1 August, the heat wave lasted about two weeks (in region North, no intermission is displayed between the previous heat wave in July and the August heat wave). The average two-daily mean $\mathrm{T}_{\mathrm{a}}$ during these heat wave days was between $21.4{ }^{\circ} \mathrm{C}$ in region North, and $26.3{ }^{\circ} \mathrm{C}$ in region South-West (Table 5). The regions West, Centre and South-West suffered from a severe increase of mortality during these days of both CLRD and IHD, however, CLRD mortality displays remarkably higher RR than IHD; up to a maximum of 1.9, 2.1 and 2.4 (West, Centre and South-West respectively). CLRD patients in region South-West had, therefore, an increased risk of death by $70 \%(R R=1.7)$ in average of the heat wave and a maximum of $140 \%(R R=2.1)$ than commonly 
in August. RR of IHD mortality was increased by between 1.1 and 1.3, with maxima of 1.6 (West, Centre) and 1.7 (South-West). These results are in agreement with the results of the full temperature range evaluation, that CLRD mortality is rising earlier with increasing temperature (i.e., lower $\mathrm{TH}_{U}$ ) and steeper than IHD mortality. The other regions were comparably less affected. The first heat wave in July 2003 displays minor increases of especially CLRD mortality (Figure 8).

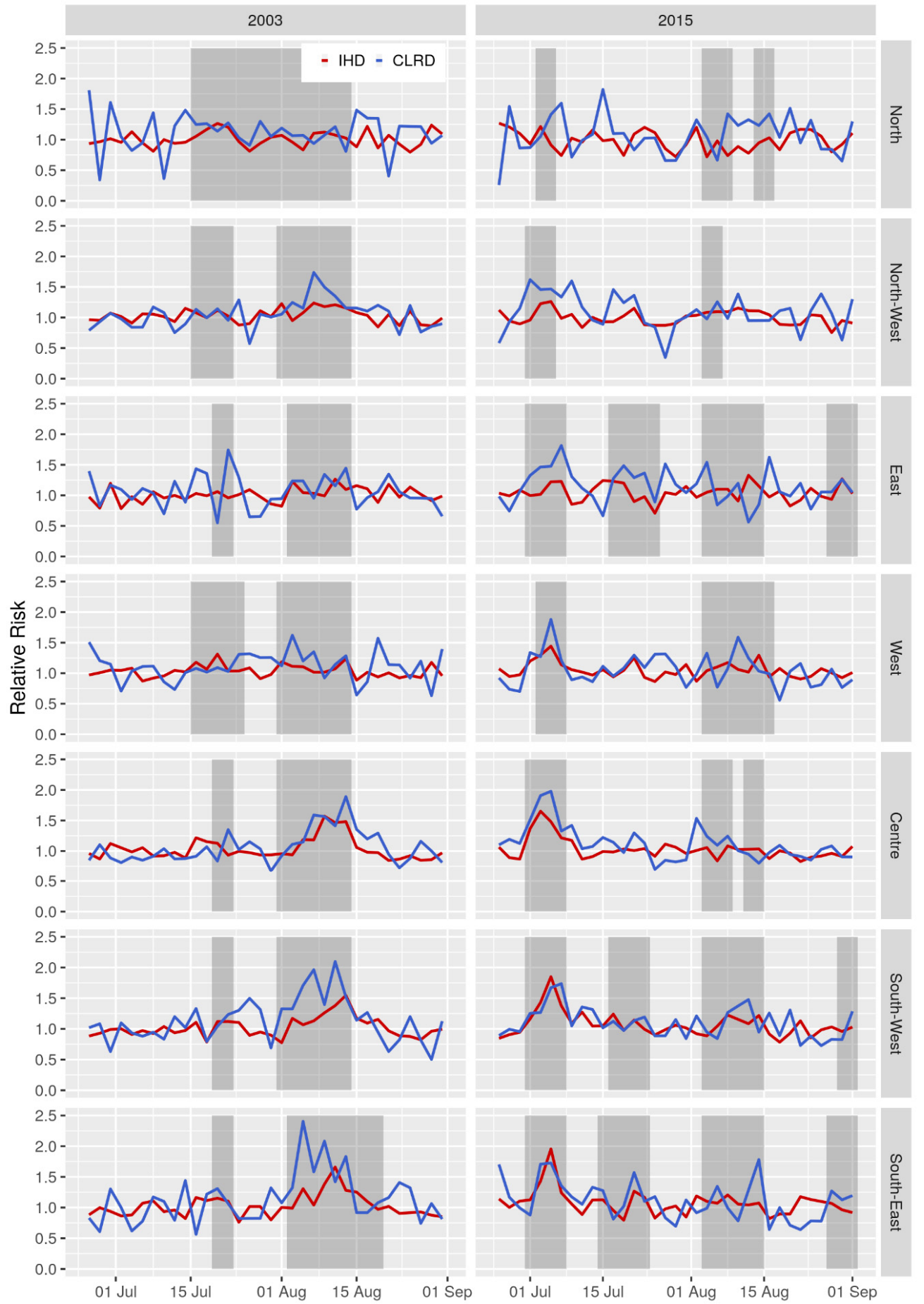

Figure 8. Relative Risk of CLRD and IHR mortality during heat waves (grey columns highlight the heat wave days) for summer 2003 (left) and summer 2015 (right), in seven regions in Germany (for regions see Figure 1). 
Table 5. Average two-daily $\mathrm{T}_{\mathrm{a}}\left({ }^{\circ} \mathrm{C}\right.$ ) as well as mean (max) of RR of CLRD (blue) and IHD (red) mortality during the heat waves of August 2003 and first part of July 2015 in seven regions in Germany.

\begin{tabular}{ccccccc}
\hline & \multicolumn{3}{c}{ Heat Wave August 2003 } & \multicolumn{3}{c}{ First Heat Wave July 2015 } \\
\hline Region & $\mathbf{T}_{\mathbf{a}}$ & RR CLRD & RR IHD & $\mathbf{T}_{\mathbf{a}}$ & RR CLRD & RR IHD \\
\hline North & 21.9 & $1.1(1.3)$ & $1.0(1.2)$ & 23.7 & $1.2(1.4)$ & $1.1(1.2)$ \\
North-West & 24.4 & $1.3(1.7)$ & $1.2(1.2)$ & 24.2 & $1.5(1.6)$ & $1.2(1.3)$ \\
East & 24.2 & $1.2(1.6)$ & $1.1(1.2)$ & 25.4 & $1.5(1.9)$ & $1.3(1.4)$ \\
West & 25.5 & $1.4(1.9)$ & $1.3(1.6)$ & 24.9 & $1.7(2.0)$ & $1.4(1.7)$ \\
Centre & 25.7 & $1.6(2.1)$ & $1.2(1.6)$ & 24.6 & $1.5(1.7)$ & $1.5(1.9)$ \\
South-West & 26.3 & $1.7(2.4)$ & $1.3(1.7)$ & 26.3 & $1.4(1.7)$ & $1.4(2.0)$ \\
South-East & 24.8 & $1.2(1.4)$ & $1.1(1.3)$ & 24.2 & $1.5(1.8)$ & $1.1(1.2)$ \\
\hline
\end{tabular}

Summer 2015 was characterized by very warm air temperature across Europe, with up to four regional heat waves in Germany (Figure 8). In comparison to the heat wave in August 2003, the first heat wave of July 2015, beginning on 1 July resp. 3 July, was substantially shorter (2-4 twin-days, see grey columns in Figure 8), but occurred also in all seven regions in Germany. The average $T_{a}$ for the first heat wave in July 2015 was slightly lower in the regions West and Centre, which were among the most affected in 2003, however $T_{a}$ was higher in the regions North and East. The distribution of heat-related CLRD mortality in 2015 displays higher RR for regions North-West, East and South-East, almost equally as high as region West and Centre. Heat-related IHD mortality shows the highest risks again in region West, Centre and South-West, even higher than 2003. The less intensive (lower $T_{a}$ ) heat waves following in July and August 2015 led to less increased mortality risk than the first heat wave in July.

Analysing these heat waves with PT as temperature parameter, the effects on mortality are similar (see Supplementary Table S6 and Figure S5). The summers 2006 and 2010 were characterized by Germany-wide heat waves as well, with increasing CLRD and IHD mortality (see also Figure 2), but the impacts on mortality at a national scale were not as strong as in 2003 and 2015.

\section{Discussion}

The analysis of thermal effects on mortality due to respiratory and ischemic heart diseases displays the negative impact of warm and hot thermal conditions. CLRD and IHD mortality are significantly increased at two-daily $\mathrm{T}_{\mathrm{a}}$, above $17.6^{\circ} \mathrm{C}$ and $18.8^{\circ} \mathrm{C}$ respectively. A cold effect occurs below $-2.7^{\circ} \mathrm{C}$ for CLRD and below $2.9^{\circ} \mathrm{C}$ for IHD. However, the cold effect for CLRD is only temporary; RR is decreasing again with lower $\mathrm{T}_{\mathrm{a}}$.

The comparison of threshold values and increases of cause-specific mortality above resp. below these thresholds is difficult between studies, because different methods, risk groups and temperature parameters are used to identify threshold values and dependent increases of mortality. One problem of temperature-related health impact assessment is that a specific percentile of temperature as threshold is commonly used in studies, but chosen only of the perspective of temperature not derived from the reaction of mortality [28-32].

Above the $\mathrm{TH}_{\mathrm{U}}$ in this study, CLRD mortality increases by $4.4 \% /{ }^{\circ} \mathrm{C}$ and IHD mortality by $3.5 \% /{ }^{\circ} \mathrm{C}$. The increase of RR of CLRD mortality is steeper with rising $T_{a}$ and displays, therefore, a greater impact of heat on CLRD compared to IHD mortality. These results agree with findings from other studies, also displaying a stronger heat effect on respiratory compared to cardiovascular mortality $[13,29,30,33]$. In a meta-analysis for elderly, Bunker, et al. [13] found increasing mortality per $1{ }^{\circ} \mathrm{C}$ rising temperature by $1.62 \%$ for IHD mortality and by $3.6 \%$ for respiratory diseases. Baccini, et al. [33] found similar gradients for north-continental European countries above a threshold of approximately $23.3^{\circ} \mathrm{C}$, with increases of cardiovascular mortality by $2.4 \% /{ }^{\circ} \mathrm{C}$, and respiratory mortality increases by $6.1 \% /{ }^{\circ} \mathrm{C}$.

Impacts of heat on the cardiovascular system are well known. Dehydration and a high sweat rate due to heat stress increases blood viscosity and the potential for thrombosis, which elevates the 
risk of cardiovascular strain and acute coronary events $[13,34,35]$. These responses are worse if the thermoregulatory capacity is limited e.g., in elderly, or due to chronic diseases of the cardiovascular or also the respiratory system. The effect of heat on respiratory health can be explained by a stressed thermoregulation triggering inflammatory factors, increasing the ventilation rate and aggravating existing respiratory diseases like COPD, leading to an exacerbation [13,36]. Especially COPD is characterized by ventilator impairment, persistent pulmonary and systematic inflammation with coexisting cardiovascular diseases [36,37]. This leads to an increased risk due to heat and could explain the predisposition of COPD patients, which are the biggest group of CLRD mortality in this study. However, Anderson, et al. [36] and Hayes Jr, et al. [38] suggest that directly inhaling hot air triggering adverse respiratory responses is rather contributing to the acute respiratory reaction than the pathway of stressed thermoregulation.

In the analysis of heat waves, the impact on CLRD mortality was found to be twice as high compared to IHD mortality (19.9\% for CLRD, 9.8\% for IHD). This confirms the higher sensitivity to heat of CLRD patients in common with findings of heat-related mortality of the full temperature range. Other investigations in Germany found similar high deviations of cardiovascular and respiratory mortality due to heat, with stronger heat effect on respiratory mortality $[10,30]$. The longer the heat waves last, the higher the deviation of mortality, until a maximum is reached and mortality deviation stays at a high level until the end of the heat wave. Investigations of effect modification by heat wave duration, intensity and timing in the season showed an increasing trend with rising temperature (intensity), duration and early timing in the season [39].

The comparison between summer 2003 and 2015 was done to evaluate RR of mortality for specific heat waves important in Germany. Most regions revealed, again, higher risk of CLRD mortality compared to IHD mortality. The August 2003 heat wave differs from the first July heat wave 2015 in higher air temperature, longer duration and drier conditions [8]. During the first heat wave in 2015, higher average PT reflects more humid conditions, which is leading in combination with its occurrence at the beginning of the season to equally high or higher RR in comparison to 2003 despite the shorter duration. In 2003, the August heat wave was not the first in the season, but due to its exceptional duration and intensity, RR of CLRD was increased up to 2.5, meaning that CLRD mortality was up to $150 \%$ higher than expected. The humid conditions in 2015 were partly amplifying the gap between CLRD and IHD mortality in the most affected regions of eastern Germany. This strengthened the assumption that CLRD mortality is more affected by humid conditions compared to IHD mortality.

Many studies reported U- or J-shaped associations between thermal environment and mortality [6,7]. This analysis can confirm these findings for the temperature range above the minimum of mortality, however, only partly for the lower temperature range. We found low and partly non-significant reactions of CLRD and IHD mortality to cold days or cold waves. Contrary to expectations, a stronger cold effect was found for IHD mortality compared to CLRD mortality. The reason for decreased mortality prior to cold waves are not yet resolved. Cofounders attributable to winter mortality like influenza could not be included in this study, due to data availability.

An increase of respiratory mortality due to higher air temperature is mostly described as distinctly stronger than the increase due to lower air temperature (e.g., [15-19]). Despite this fact, respiratory diseases are also linked to cold temperature, and several studies state an increased risk of respiratory mortality with decreasing temperature [20-22]. Other studies comparing cold impact on respiratory and cardiovascular (CVD) mortality found significant increases of respiratory mortality and lower or non-significant cold effect on CVD mortality $[13,40,41]$. Low temperature often triggers a lagged reaction of mortality days to weeks (e.g., [29,41,42]), while heat causes more immediate health effects increasing already in the first days of heat $[43,44]$. In this analysis, consideration of a lag up to 12 days is leading to an increased cold impact on CLRD and IHD mortality, but also to an increased heat impact. Moreover, Breitner, et al. [29] had found similar results to this study referring to the lag effect with a remarkable increase of heat-related mortality, considering a lag up to 14 days, especially of respiratory mortality. 
A possible explanation of the slight reaction of CLRD on cold conditions could be the choice of diagnoses included in the investigation. CLRD include only chronic diseases of the lower respiratory tract like asthma and COPD, but not acute infections like influenza or pneumonia, which could be more linked to cold conditions. Furthermore, these chronic patients could have more awareness of the risk of cold conditions and take precautions but less awareness of the risk of heat.

The results of the regional analyses reveal a tendency to lower sensitivity to cold in the northern and eastern regions of Germany, which is characterized by cooler maritime resp. continental climate. South-Western Germany experience warm and humid conditions more often, and therefore we found higher threshold values of heat stress, which suggest an adaptation to these conditions. However, during heat events, the risk of CLRD and IHD mortality increases more and more steeply compared to other regions. Researchers are discussing effect modification of heat and cold effect by air pollution, like ozone, nitrogen dioxide and particulate matter (e.g., [29,33,45]). The impact of air pollution on health and its confounding effect on the temperature-mortality relationship was not investigated in this study. In a widespread meta-analysis for elderly, Bunker et al. [13] found only small to moderate effect modifications on mortality in analyses controlling for air pollution. However, on the one hand, air pollution is important to capture the entire causal effect; on the other hand, the adjustment for air pollution could block a part of the total effect of temperature on mortality due to the interaction of temperature with air pollution like ozone [46].

Analysing both PT and $\mathrm{T}_{\mathrm{a}}$ reveals only minor differences in the association with mortality (for results of PT, see supplement) due to a high correlation coefficient. The J-shaped relationship is very similar for $\mathrm{PT}$ and $\mathrm{T}_{\mathrm{a}}$ displaying the minimum of $\mathrm{RR}$ in the middle of temperature range, a minor and slow increase towards low temperatures, and a steep and strong increase with rising temperature for both CLRD and IHD. Despite the slightly lower correlation between PT and $\mathrm{T}_{\mathrm{a}}$ during heat and cold waves, the differences in the effect on mortality were minor as well. In spite of the simplicity of $\mathrm{T}_{\mathrm{a}}$ compared to $\mathrm{PT}$, which includes humidity, radiation, wind speed and a physiological model, $\mathrm{T}_{\mathrm{a}}$ seems to be equally qualified to display the temperature-related mortality, at least on a basis of two-daily average values. This is in agreement with findings of e.g., Barnett, et al. [47], who couldn't find a superior temperature measure with or without including humidity for modelling all-cause mortality in over 100 US-cities, but large differences between regions and age groups. Vaneckova, et al. [48] showed that average temperature performs comparable analysis results of temperature-related all-cause mortality, similarly to composite indices. Nevertheless, if all necessary input parameters are available, the usage of a human biometeorological index is more appropriate to represent thermal environment [21], particularly by using higher temporal resolution or daily maximum or minimum temperature. Despite the indication that CLRD mortality is more affected by humid conditions during the heat wave in July 2015, this assumption could not be verified in the comparison between results based on $\mathrm{PT}$ and $\mathrm{T}_{\mathrm{a}}$.

Meteorological parameters were derived from stations located outside of cities (e.g., airports). However, the majority of the population are living in cities, and are therefore affected by climatic effects of urban structures, like urban heat islands. An effect modification by urban effects could not be considered due to the given data availability. Another limitation of the study is the lack of sex or age differentiating in mortality data, due to the low case number of CLRD mortality. Other investigations found high mortality risks due to heat, especially among elderly $[29,33]$. CLRD data was available in two-daily rates only. However, by transforming daily IHD rates to two-daily resolution, only minor differences in the relationship to temperature were found to not impair the interpretation of results. To evaluate the findings of this study, a sensitivity analysis using a regression model and integrating further confounders would be recommended for future studies, improving also the comparison of the findings with other analyses in literature.

The strengths of this study are the direct comparison of chronic respiratory and ischemic heart mortality in Germany, as well as the comparison of heat and cold effects within the same study. To the best of the authors' knowledge, this was not yet conducted for the whole of Germany in the last 
20 years. The regional resolution enables one to present threshold values for heat and cold effects in different climatic regions in Germany.

\section{Conclusions}

The aim of this study was to analyse the impact of the thermal environment on CLRD mortality compared to IHD mortality on a regional level in Germany. The results clarify the difference in the impact of heat stress with significant increases of mortality, compared to low temperature with low to non-significant impacts on mortality. Therefore, improving current and future health services during heat events is indispensable and requires more attention compared to cold impacts. The examination of the aptitude of PT and $\mathrm{T}_{\mathrm{a}}$ for the association with mortality resulted in only minor differences enabling both parameters equally. However, this conclusion is only valid for two-daily averages of the temperature parameter, not for higher temporal resolutions. The comparison between ischemic heart and chronic respiratory mortality highlights the concern of CLRD patients due to heat stress. This conclusion could help to raise awareness of the risks, and to take precautions for chronic respiratory patients, which are already established for cardiac patients in Germany.

Considering the projected increase of heat events due to climate change, understanding the risk of thermal environment on human health is essential. An analysis of changing climate until the end of the 21st century in Germany, and its consequences for ischemic and respiratory diseases are planned for future studies.

Supplementary Materials: The following are available online at http://www.mdpi.com/2073-4433/11/8/826/s1, Figure S1: Expected value of IHD mortality with population-based two-day rate (yellow), result of the Gaussian low-pass filter (light blue), the corrected filter function of expected value (dark blue) and the residuals (grey). Marked in red are the deviations of mortality during the summers 2003, 2006, 2010 and 2015. Figure S2. Relationship between PT and RR of CLRD and IHD mortality in the years 2001-2015 in Germany. Table S1. Lower (THL) and upper (THU) threshold values of PT of CLRD mortality (blue) and IHD mortality (red) as well as the gradients of RR below resp. above these TH for Germany and its seven regions. Significant gradients on 95\% level $(\alpha=0.05)$ are marked in bold. Table S2. Difference between heat waves based on $\mathrm{T}_{\mathrm{a}}$ and based on PT for the years 2001-2015 for seven regions in Germany. Consensus between both methods is depicted as percentage of dates identified as heat wave by Ta, which are identified by PT as well. Figure S3. Deviation of CLRD (blue) and IHD (red) mortality from the expected value due to heat waves based on PT. Left: Averaged over all heat waves between 2001-2015 in Germany. Right: Days before, during and after 6-day (3 twin days) heat waves in Germany averaged over the years 2001-2015. Table S3. Deviation of CLRD (blue) and IHD (red) mortality during heat waves based on PT. Significant deviations on 95\% level $(\alpha=0.05)$ are marked in bold. Table S4. Difference between cold waves based on $\mathrm{T}_{\mathrm{a}}$ and based on PT for the years 2001-2015 for seven regions in Germany. Consensus between both methods is depicted as percentage of dates identified as cold wave by $T_{a}$, which are identified by PT as well. Figure S4. Deviation of CLRD (blue) and IHD (red) mortality from the expected value due to cold waves based on PT. Left: Averaged over all cold waves between 2001-2015 in Germany. Right: Days before, during and after 6-day (3 twin-days) cold waves in Germany averaged over the years 2001-2015. Table S5. Deviation of CLRD and IHD mortality during cold waves based on PT. Significant deviations on $95 \%$ level $(a<0.5)$ are marked in bold. Table S6. Average two-daily PT [ $\left.{ }^{\circ} \mathrm{C}\right]$ as well as mean (max) of RR of CLRD (blue) and IHD (red) mortality during the heat waves of August 2003 and first part of July 2015 in seven regions in Germany. Figure S5. Relative Risk of CLRD and IHR mortality during heat waves based on PT (grey columns highlight the heat wave days) for summer 2003 (left) and summer 2015 (right) in seven regions in Germany.

Author Contributions: Conceptualization, I.S., S.M. and A.M.; methodology, S.M. and I.S.; software, I.S. and S.M.; validation, S.M.; formal analysis, I.S. and S.M.; investigation, I.S. and S.M.; resources, A.M. and H.-G.M.; data curation, S.M. and I.S.; writing-original draft preparation, I.S.; writing-review and editing, S.M., A.M. and H.-G.M.; visualization, I.S.; supervision, A.M. and H.-G.M.; project administration, S.M., A.M. and H.-G.M.; funding acquisition, H.-G.M. and A.M. All authors have read and agreed to the published version of the manuscript.

Funding: This research received no external funding.

Acknowledgments: This study is part of the UFOPLAN project "Impact of Climate Change on seasonal morbidity and mortality of respiratory diseases" (funded by the Federal Ministry for the Environment, Nature Conservation and Nuclear Safety), supporting the German Adaption Strategy to Climate Change.

Conflicts of Interest: The authors declare no conflict of interest. 


\section{References}

1. Steppuhn, H.; Buda, S.; Wienecke, A.; Kraywinkel, K.; Tolksdorf, K.; Haberland, J.; Laußmann, D.; Scheidt-Nave, C. Zeitliche Trends in der Inzidenz und Sterblichkeit respiratorischer Krankheiten von hoher Public-Health-Relevanz in Deutschland. J. Health Monit. 2017, 2, 33. [CrossRef]

2. Destatis. Gesundheit-Todesursachen in Deutschland 2015; Statistisches Bundesamt: Wiesbaden, Germany, 2017; Volume Fachserie.

3. Rabe, K.F.; Hurd, S.; Anzueto, A.; Barnes, P.J.; Buist, S.A.; Calverley, P.; Fukuchi, Y.; Jenkins, C.; Rodriguez-Roisin, R.; Van Weel, C. Global strategy for the diagnosis, management, and prevention of chronic obstructive pulmonary disease: GOLD executive summary. Am. J. Respir. Crit. Care Med. 2007, 176, 532-555. [CrossRef] [PubMed]

4. Steppuhn, H.; Kuhnert, R.; Scheidt-Nave, C. 12-Monats-Prävalenz von Asthma bronchiale bei Erwachsenen in Deutschland. J. Health Monit. 2017, 2, 36-45. [CrossRef]

5. Destatis. Gesundheitswesen-Todesursachen in Deutschland 2001; Statistisches Bundesamt: Wiesbaden, Germany, 2003; Volume Fachserie.

6. Laaidi, M.; Laaidi, K.; Besancenot, J.P. Temperature-related mortality in France, a comparison between regions with different climates from the perspective of global warming. Int. J. Biometeorol. 2006, 51, 145-153. [CrossRef]

7. Breitner, S.; Wolf, K.; Peters, A.; Schneider, A. Short-term effects of air temperature on cause-specific cardiovascular mortality in Bavaria, Germany. Heart 2014, 100, 1272-1280. [CrossRef]

8. Muthers, S.; Laschewski, G.; Matzarakis, A. The summers 2003 and 2015 in south-west Germany: Heat waves and heat-related mortality in the context of climate change. Atmosphere 2017, 8, 224. [CrossRef]

9. DWD. Deutscher Wetterdienst-Time Series and Trends. Available online: https://www.dwd.de/EN/ ourservices/zeitreihen/zeitreihen.html (accessed on 7 July 2020).

10. Hoffmann, B.; Hertel, S.; Boes, T.; Weiland, D.; Jockel, K.H. Increased cause-specific mortality associated with 2003 heat wave in Essen, Germany. J. Toxicol. Environ. Health. Part A 2008, 71, 759-765. [CrossRef] [PubMed]

11. IPCC. Summary for policymakers. In Climate Change 2013: The Physical Science Basis, Contribution of Working Group I to the Fifth Assessment Report of the Intergovernmental Panel on Climate Change; Stocker, T., Qin, D., Plattner, G., Tignor, M., Allen, S., Boschung, J., Nauels, A., Xia, Y., Bex, V., Midgley, P., Eds.; Cambridge University Press: Cambridge UK; New York, NY, USA, 2013.

12. Arbuthnott, K.G.; Hajat, S. The health effects of hotter summers and heat waves in the population of the United Kingdom: A review of the evidence. Environ. Health A Glob. Access Sci. Source 2017, 16, 119. [CrossRef]

13. Bunker, A.; Wildenhain, J.; Vandenbergh, A.; Henschke, N.; Rocklöv, J.; Hajat, S.; Sauerborn, R. Effects of air temperature on climate-sensitive mortality and morbidity outcomes in the elderly; a systematic review and meta-analysis of epidemiological evidence. EBioMedicine 2016, 6, 258-268. [CrossRef] [PubMed]

14. Phung, D.; Thai, P.K.; Guo, Y.; Morawska, L.; Rutherford, S.; Chu, C. Ambient temperature and risk of cardiovascular hospitalization: An updated systematic review and meta-analysis. Sci. Total Environ. 2016, 550, 1084-1102. [CrossRef] [PubMed]

15. Song, X.; Wang, S.; Hu, Y.; Yue, M.; Zhang, T.; Liu, Y.; Tian, J.; Shang, K. Impact of ambient temperature on morbidity and mortality: An overview of reviews. Sci. Total Environ. 2017, 586, 241-254. [CrossRef] [PubMed]

16. Sun, Z.; Chen, C.; Xu, D.; Li, T. Effects of ambient temperature on myocardial infarction: A systematic review and meta-analysis. Environ. Pollut. 2018, 241, 1106-1114. [CrossRef] [PubMed]

17. Zacharias, S.; Koppe, C.; Mücke, H.-G. Climate Change Effects on Heat Waves and Future Heat Wave-Associated IHD Mortality in Germany. Climate 2015, 3, 100-117. [CrossRef]

18. Zacharias, S.; Koppe, C.; Mücke, H.-G. Influence of heat waves on ischemic heart diseases in Germany. Climate 2014, 2, 133-152. [CrossRef]

19. Chen, K.; Breitner, S.; Wolf, K.; Hampel, R.; Meisinger, C.; Heier, M.; von Scheidt, W.; Kuch, B.; Peters, A.; Schneider, A. Temporal variations in the triggering of myocardial infarction by air temperature in Augsburg, Germany, 1987-2014. Eur. Heart J. 2019, 40, 1600-1608. [CrossRef]

20. Staiger, H.; Laschewski, G.; Grätz, A. The perceived temperature-a versatile index for the assessment of the human thermal environment. Part A: Scientific basics. Int. J. Biometeorol. 2012, 56, 165-176. [CrossRef] 
21. Staiger, H.; Laschewski, G.; Matzarakis, A. Selection of appropriate thermal indices for applications in human biometeorological studies. Atmosphere 2019, 10, 18. [CrossRef]

22. Matzarakis, A.; Rutz, F.; Mayer, H. Modelling radiation fluxes in simple and complex environments: Basics of the RayMan model. Int. J. Biometeorol. 2010, 54, 131-139. [CrossRef]

23. Koppe, C.; Jendritzky, G. Inclusion of short-term adaptation to thermal stresses in a heat load warning procedure. Meteorol. Z. 2005, 14, 271-278. [CrossRef]

24. Laschewski, G.; Jendritzky, G. Effects of the thermal environment on human health: An investigation of 30 years of daily mortality data from SW Germany. Clim. Res. 2002, 21,91-103. [CrossRef]

25. Schönwiese, C.D. Praktische Statistik für Meteorologen und Geowissenschaftler (Practical Statistics for Meteorologists and Geoscientists), 3 ed.; Gebrüder Bornträger Verlag: Berlin, Germany; Stuttgart, Germany, 2000; p. 298.

26. Taubenheim, J. Statistische Auswertung geophysikalischer und meteorologischer Daten In Geographische Monographien; Akademische Verlagsgesellschaft Geest und Portig: Leipzig, Germany, 1969; Volume 5, pp. 311-345.

27. Team, R.C. R: A Language and Environment for Statistical Computing; R Foundation for Statistical Computing: Vienna, Austria, 2019.

28. Basu, R.; Malig, B. High ambient temperature and mortality in California: Exploring the roles of age, disease, and mortality displacement. Environ. Res. 2011, 111, 1286-1292. [CrossRef]

29. Breitner, S.; Wolf, K.; Devlin, R.B.; Diaz-Sanchez, D.; Peters, A.; Schneider, A. Short-term effects of air temperature on mortality and effect modification by air pollution in three cities of Bavaria, Germany: A time-series analysis. Sci. Total Environ. 2014, 485-486, 49-61. [CrossRef] [PubMed]

30. D’Ippoliti, D.; Michelozzi, P.; Marino, C.; de’Donato, F.; Menne, B.; Katsouyanni, K.; Kirchmayer, U.; Analitis, A.; Medina-Ramon, M.; Paldy, A.; et al. The impact of heat waves on mortality in 9 European cities: Results from the EuroHEAT project. Environ. Health 2010, 9, 37. [CrossRef]

31. Gasparrini, A.; Armstrong, B.; Kovats, S.; Wilkinson, P. The effect of high temperatures on cause-specific mortality in England and Wales. Occup. Environ. Med. 2012, 69, 56-61. [CrossRef] [PubMed]

32. Hajat, S.; Kovats, R.S.; Atkinson, R.W.; Haines, A. Impact of hot temperatures on death in London: A time series approach. J. Epidemiol. Community Health 2002, 56, 367-372. [CrossRef]

33. Baccini, M.; Biggeri, A.; Accetta, G.; Kosatsky, T.; Katsouyanni, K.; Analitis, A.; Anderson, H.R.; Bisanti, L.; D'ippoliti, D.; Danova, J. Heat effects on mortality in 15 European cities. Epidemiology 2008, 19, 711-719. [CrossRef]

34. Cheng, X.; Su, H. Effects of climatic temperature stress on cardiovascular diseases. Eur. J. Intern. Med. 2010, 21, 164-167. [CrossRef]

35. Keatinge, W.R.; Coleshaw, S.R.; Easton, J.C.; Cotter, F.; Mattock, M.B.; Chelliah, R. Increased platelet and red cell counts, blood viscosity, and plasma cholesterol levels during heat stress, and mortality from coronary and cerebral thrombosis. Am. J. Med. 1986, 81, 795-800. [CrossRef]

36. Anderson, G.B.; Dominici, F.; Wang, Y.; McCormack, M.C.; Bell, M.L.; Peng, R.D. Heat-related emergency hospitalizations for respiratory diseases in the Medicare population. Am. J. Respir. Crit. Care Med. 2013, 187, 1098-1103. [CrossRef]

37. Mannino, D.; Watt, G.; Hole, D.; Gillis, C.; Hart, C.; McConnachie, A.; Smith, G.D.; Upton, M.; Hawthorne, V.; Sin, D. The natural history of chronic obstructive pulmonary disease. Eur. Respir. J. 2006, 27, 627-643. [CrossRef]

38. Hayes, D., Jr.; Collins, P.B.; Khosravi, M.; Lin, R.-L.; Lee, L.-Y. Bronchoconstriction triggered by breathing hot humid air in patients with asthma: Role of cholinergic reflex. Am. J. Respir. Crit. Care Med. 2012, 185, 1190-1196. [CrossRef] [PubMed]

39. Anderson, G.B.; Bell, M.L. Heat waves in the United States: Mortality risk during heat waves and effect modification by heat wave characteristics in 43 US communities. Environ. Health Perspect. 2011, 119, $210-218$. [CrossRef] [PubMed]

40. Analitis, A.; Katsouyanni, K.; Biggeri, A.; Baccini, M.; Forsberg, B.; Bisanti, L.; Kirchmayer, U.; Ballester, F.; Cadum, E.; Goodman, P. Effects of cold weather on mortality: Results from 15 European cities within the PHEWE project. Am. J. Epidemiol. 2008, 168, 1397-1408. [CrossRef] [PubMed]

41. Carder, M.; McNamee, R.; Beverland, I.; Elton, R.; Cohen, G.R.; Boyd, J.; Agius, R.M. The lagged effect of cold temperature and wind chill on cardiorespiratory mortality in Scotland. Occup. Environ. Med. 2005, 62, 702-710. [CrossRef] 
42. Revich, B.; Shaposhnikov, D. Temperature-induced excess mortality in Moscow, Russia. Int. J. Biometeorol. 2008, 52, 367-374. [CrossRef]

43. Monteiro, A.; Carvalho, V.; Oliveira, T.; Sousa, C. Excess mortality and morbidity during the July 2006 heat wave in Porto, Portugal. Int. J. Biometeorol. 2013, 57, 155-167. [CrossRef]

44. Monteiro, A.; Velho, S. Health heat stress in the Porto Metropolitan Area-A matter of temperature or inadequate adaptation? Erde 2014, 145, 80-95.

45. Burkart, K.; Canário, P.; Breitner, S.; Schneider, A.; Scherber, K.; Andrade, H.; Alcoforado, M.J.; Endlicher, W. Interactive short-term effects of equivalent temperature and air pollution on human mortality in Berlin and Lisbon. Environ. Pollut. 2013, 183, 54-63. [CrossRef]

46. Buckley, J.P.; Samet, J.M.; Richardson, D.B. Commentary: Does air pollution confound studies of temperature? Epidemiology 2014, 25, 242-245. [CrossRef]

47. Barnett, A.G.; Tong, S.; Clements, A.C. What measure of temperature is the best predictor of mortality? Environ. Res. 2010, 110, 604-611. [CrossRef]

48. Vaneckova, P.; Neville, G.; Tippett, V.; Aitken, P.; FitzGerald, G.; Tong, S. Do biometeorological indices improve modeling outcomes of heat-related mortality? J. Appl. Meteorol. Climatol. 2011, 50, 1165-1176. [CrossRef]

(C) 2020 by the authors. Licensee MDPI, Basel, Switzerland. This article is an open access article distributed under the terms and conditions of the Creative Commons Attribution (CC BY) license (http://creativecommons.org/licenses/by/4.0/). 